\title{
Assessment of the antimicrobial properties of fractions obtained from bryophytes
}

\author{
Olofin, T. A. ${ }^{*}$, Akande, A. O. and Oyetayo, V. O. \\ University of Ado-Ekiti and The Federal University of Technology, P.M.B. 702, Akure, Nigeria \\ Accepted 4 December 2012
}

\begin{abstract}
Water, ethanol and acetone extracts were obtained from 10 selected bryophytes (seven mosses and three liverworts) viz: Radula flacida, Cyatodium africanum, Frullania spongiosa, Thuidium gratum, Ectropothecium aeruginosum, Sematophyllum caespitosum, Stereophyllum radiculosum, Babula lamberenensis, Campilopus aspericuspis and Calymperes erosum. A total of 24 fractions of various colors were obtained through a column chromatography. The antimicrobial efficacy of these fractions was assessed against Candida albicans, Staphylococcus aureus, Penicillum notatum and Mucor rouxii. Fractions obtained from $R$. flacida suppressed the growth of $C$. albicans, $S$. aureus and $M$. rouxii. Cyatodium aficanum was also effective against $M$. rouxii. None of the fractions of these plants could antagonize the growth of $P$. notatum. The results obtained from this study indicate that effective antimicrobial compounds can be sourced from $R$. flacida and $C$. africanum.
\end{abstract}

Key words: Water, ethanol, acetone extracts, bryophytes, antimicrobial efficacy.

\section{INTRODUCTION}

The search for effective antimicrobial agents had increased of recent. The major reason for this is the increasing resistance posed by microorganisms to commercial antibiotics. Plants such as bryophytes are known to contain phytochemicals that can serve as effective antimicrobial agents, some of these useful bryophytes compounds include; oligosaccharides, polysaccharides, sugar alcohols, amino acids, fatty acids, aliphatic compounds, phenyl quinines, aromatic and phenolic substances, but much work has not been done to link medicinal effects with specific bryophytes species (William et al., 2005). Byophytes species produce a broad range of antibiotics and the degree of antibiotic activity in a given species may depend on the age of the gametophyte (Subramoriams and Subhisiha, 2005). The active ingredients responsible for antimicrobial effects have been isolated and identified from several bryophytes, such as Polygodial from Porella, Norpiguisone from Conocephalum conicum and Lunularin from Lunularia cruciata. Some liverworts also have some

\footnotetext{
${ }^{*}$ Corresponding author. E-mail: olofintiti@yahoo.com.
}

anti-leukemia activity, for example Diplophyllin was isolated from Diplophyllum albicans and Diplophyllum taxifolium, which have significant activity against human epidermoid carcinoma (Saxena and Harinder, 2004). Some of the medicinal species recognized are; Hepaticea (Frullania tamarisci, Reboulia hemispherica, Conocephalum, Conocephalum supradecompositum and Marchantia polymorpha), Musci (Sphagnum girgensolinii, Sphagnum magellanicum, Sphagnum Palustre, Sphagnum teres, Rhodobryum giganteum and Rhodobryum roseum). Conocephalum conicum, Mnium undulatum and Leptodictyum riparium have strong antibacterial activity against pathogenic bacteria species. Similarly, Rhynchostegium riparioides extract has good antibacterial activity against Gram negative bacteria, in particular Escherichia coli, Proteus mirabilis, Enterobacter cloacae and Pseudomonas aeruginosa (Basile et al., 1998). Petroleum-ether extracts of Barbula and Timmiella species have antibacterial activity against both Gram-positive and Gram-negative bacteria (Subramoniam and Subhisha, 2005).

One danger in using bryophytes is that the same compounds that may have antibiotic properties may also 
be toxic or allergenic, or be associated with such compounds, thus many antibiotics have been isolated from bryophytes, but few have been developed for medical use, despite their demonstrated effectiveness. Nigeria in West Africa, is a home to varieties of these bryophytes and some of the common species in Nigeria include; Jaegerina scariosa (Lor.) Arz., Octoblepharum albidum Hedw. Racopilum africanum MITT., Barbula lambarenensis C. Mull and Philonotis hastata (Akande, 1992). However, there is little or no information on the antimicrobial effects of these African species of bryophyte plants. The present study is therefore meant to assess the antimicrobial properties of some of these plants on some indicator microorganisms.

\section{MATERIALS AND METHODS}

\section{Sample collection}

Some bryophytes were collected from the wall of buildings, some from the floor in the wild, some from the bark of trees, including the bark of palm trees, some from the river bank and others from the bark of fallen trees and logs in Ado - Ekiti, Ekiti State, Nigeria. All these collections were kept in herbarium packets and brought to the herbarium unit, Department of plant science, Ekiti State University, Ado - Ekiti, Ekiti State, Nigeria for proper observation and identification. These samples were then collected fresh from the field and used for the experiment. A total of 15 samples of bryophytes namely; Calymperes erosum, Barbula lamberenensis, Radula flacida, Sematophylum caespitosum, Stereophyllum radiculosum, Thuidium gratum, Ectropothecium aeruginosum, Cyatodium africanum, Campylopus aspericuspis, Frullania spongiosa, Polytricum commune, Marchantia polymorpha, Rhodobryum giganteum, Lapholejeunea subfusca and Pohlia cruda were collected from the field, but only 10 species were used for the subsequent experiment based on their abundance and proximity.

\section{Extraction of biologically active substance}

Water, ethanol and acetone extracts were obtained from the 10 selected bryophytes (seven mosses and three liverworts) viz; $R$. flacida, C. africanum, F. spongiosa, T. gratum, Ectropothecium aeruginosum, Sematophyllum caespitosum, S. radiculosum, Babula lamberenensis, $C$. aspericuspis and $C$. erosum. In a mortar with pestle, $2 \mathrm{~g}$ of each of the plant samples was separately ground in 5 $\mathrm{ml}$ of distilled water, until homogenous slurry was obtained. This slurry was sieved through a sterile muslin cloth to discard the residue. The supernatants were collected in sterile labeled test tubes and covered with aluminum foil paper. The procedure above was also repeated for ethanol and acetone extracts (Alanis et al., 2005). The supernatants were further separated in a column chromatogram which was made of cellulose powder. A total of 24 fractions of various colors were obtained through a column chromatography.

\section{Determination of antibacterial activity of the extracts}

Sensitivity test was done by using agar diffusion of Kirby-Bauer's procedure for the evaluation of the antimicrobial activity of chemotherapeutic agents by using extracts that have already been filter separated in the chromatogram, sample $(0.1 \mathrm{ml})$ was carefully transferred into each well of already prepared plates of the test organisms which were grown in Mueller Hinton Agar (MHA, Oxoid) for $24 \mathrm{~h}$ at $37^{\circ} \mathrm{C}$ and they were labeled appropriately. The microbial load after this incubation period was determined. Sterile distilled water was added $(0.1 \mathrm{ml})$ into the second holes and served as the control. The plates were incubated un-inverted at $37^{\circ} \mathrm{C}$ for $24 \mathrm{~h}$. The zones of inhibition were measured with a ruler in millimeters, and the results were recorded. The minimum inhibitory concentration (MIC) was determined as the lowest concentration that completely inhibited macroscopic growth of the organisms.

\section{Standard antibiotic sensitivity test}

About $0.1 \mathrm{ml}$ of $18 \mathrm{~h}$ broth culture of each of the test organism was inoculated unto the surface of the set agar on different Petri dishes in triplicates. The inoculums were spread on the surface of the agar with the aid of sterile hockey stick. Standard antibiotic disc were aseptically placed at a central position on the surface of the agar plates using a sterile forceps, it was then pressed gently against the inoculated plates. The plates were then incubated in an inverted position at $37^{\circ} \mathrm{C}$ for $24 \mathrm{~h}$. Zones of inhibition around the discs were measured.

\section{RESULTS}

From the results obtained in this study, some of the test organisms were susceptible to the fractions obtained from these plants and the pattern of their susceptibility was in accordance with their minimum inhibitory concentrations, for instance those fractions with low value of MIC are more active than the fractions with higher value of MIC. A total of 24 fractions of various colors were obtained from extracts of the 10 bryophytes through a column chromatography. Only two out of 10 species of bryophytes tested that is, C. africanum and R. flacida, showed antimicrobial effect on some of the test microorganisms used.

In this study, ethanol extract of $R$. flacida suppressed the growth of Staphylococcus aureus and micrococcus spp in culture having 10.0 and $8.0 \mathrm{~mm}$ diameter zone of inhibition with minimum inhibitory concentrations of 20.50 and $24.50 \mu \mathrm{g} / \mathrm{ml}$, respectively. Water extract from $R$. flacida also displayed antimicrobial effect against Mucor rouxii with $7.0 \mathrm{~mm}$ zone of inhibition and minimum inhibitory concentration of $26.50 \mu \mathrm{g} / \mathrm{ml}$. Water extracts from $C$. africanum gave positive effect on $M$. rouxii also with $9.0 \mathrm{~mm}$ zone of inhibition and MIC of $22.60 \mu \mathrm{g} / \mathrm{ml}$ (Table 4). S. aureus showed the highest sensitivity to ethanol extract of $R$. flacida, then next to it is $M$. rouxii, which was sensitive to water and ethanol extracts of $C$. africanum and the least sensitivity occurred in water extract of $R$. flacida against $M$. rouxii. All the remaining tested microorganisms did not show any sensitivity to all the concentrations of Calymperes erosum, Barbula lamberenensis, Sematophylum caespitosum, Stereophyllum radiculosum, T. gratum, Ectropothecium aeruginosa, Campylopus aspericuspis, Frullania spongiosa, Polytricum commune, Marchantia polymorpha, 
Table 1. Antimicrobial effect of water extracts from bryophytes.

\begin{tabular}{lcccccccccc}
\hline \multirow{2}{*}{ Microorganism } & \multicolumn{10}{c}{ Zone of inhibition (mm) } \\
\cline { 2 - 11 } & $\mathbf{1}$ & $\mathbf{2}$ & $\mathbf{3}$ & $\mathbf{4}$ & $\mathbf{5}$ & $\mathbf{6}$ & $\mathbf{7}$ & $\mathbf{8}$ & $\mathbf{9}$ & $\mathbf{1 0}$ \\
\hline Candida albicans & 0 & 0 & 0 & 0 & 0 & 0 & 0 & 0 & 0 & 0 \\
Pseudomonas aeruginosa & 0 & 0 & 0 & 0 & 0 & 0 & 0 & 0 & 0 & 0 \\
Staphylococcus aureus & 0 & 0 & 0 & 0 & 0 & 0 & 0 & 0 & 0 & 0 \\
Botrytis cinera & 0 & 0 & 0 & 0 & 0 & 0 & 0 & 0 & 0 & 0 \\
Rhizoctonia solani & 0 & 0 & 0 & 0 & 0 & 0 & 0 & 0 & 0 & 0 \\
Phythium debaryanium & 0 & 0 & 0 & 0 & 0 & 0 & 0 & 0 & 0 & 0 \\
Escherichia coli & 0 & 0 & 0 & 0 & 0 & 0 & 0 & 0 & 0 & 0 \\
Klebsiella spp & 0 & 0 & 0 & 0 & 0 & 0 & 0 & 0 & 0 & 0 \\
Bacillus cereus & 0 & 0 & 0 & 0 & 0 & 0 & 0 & 0 & 0 & 0 \\
Micrococcus spp & 0 & 0 & 0 & 0 & 0 & 0 & 0 & 0 & 0 & 0 \\
Proteus spp & 0 & 0 & 0 & 0 & 0 & 0 & 0 & 0 & 0 & 0 \\
Aspergillus flavus & 0 & 0 & 0 & 0 & 0 & 0 & 0 & 0 & 0 & 0 \\
Mucor rouxeii & 0 & 0 & 0 & 0 & 9.0 & 7.0 & 0 & 0 & 0 & 0 \\
Penicillum spp & 0 & 0 & 0 & 0 & 0 & 0 & 0 & 0 & 0 & 0 \\
Botryodiploida theobromae & 0 & 0 & 0 & 0 & 0 & 0 & 0 & 0 & 0 & 0 \\
\hline
\end{tabular}

1, Thuidium gratum; 2, Ectopothecium aerginosum; 3, Calymperes erosum; 4, Sematophyllum caespitosum; 5, Cyatodium africanum; 6, Radula flacida: 7, Barbula lamberenensis; 8, Steriophyllum radiculosum; 9, Camphylopus aspecicuspsis; 10, Frullania spongiosa. Values are mean of replicates.

Table 2. Antimicrobial effect of Acetone extracts from bryophytes.

\begin{tabular}{lcccccccccc}
\hline \multirow{2}{*}{ Microorganism } & \multicolumn{110}{c}{ Zone of inhibition $(\mathbf{m m})$} \\
\cline { 2 - 12 } & $\mathbf{1}$ & $\mathbf{2}$ & $\mathbf{3}$ & $\mathbf{4}$ & $\mathbf{5}$ & $\mathbf{6}$ & $\mathbf{7}$ & $\mathbf{8}$ & $\mathbf{9}$ & $\mathbf{1 0}$ \\
\hline Candida albicans & 0 & 0 & 0 & 0 & 0 & 0 & 0 & 0 & 0 & 0 \\
Pseudomonas aeruginosa & 0 & 0 & 0 & 0 & 0 & 0 & 0 & 0 & 0 & 0 \\
Staphylococcus aureus & 0 & 0 & 0 & 0 & 0 & 0 & 0 & 0 & 0 & 0 \\
Botrytis cinera & 0 & 0 & 0 & 0 & 0 & 0 & 0 & 0 & 0 & 0 \\
Rhizoctonia solani & 0 & 0 & 0 & 0 & 0 & 0 & 0 & 0 & 0 & 0 \\
Phythium debaryanium & 0 & 0 & 0 & 0 & 0 & 0 & 0 & 0 & 0 & 0 \\
Escherichia coli & 0 & 0 & 0 & 0 & 0 & 0 & 0 & 0 & 0 & 0 \\
Klebsiella spp & 0 & 0 & 0 & 0 & 0 & 0 & 0 & 0 & 0 & 0 \\
Bacillus cereus & 0 & 0 & 0 & 0 & 0 & 0 & 0 & 0 & 0 & 0 \\
Micrococcus spp & 0 & 0 & 0 & 0 & 0 & 0 & 0 & 0 & 0 & 0 \\
Proteus spp & 0 & 0 & 0 & 0 & 0 & 0 & 0 & 0 & 0 & 0 \\
Aspergillus flavus & 0 & 0 & 0 & 0 & 0 & 0 & 0 & 0 & 0 & 0 \\
Mucor rouxeii & 0 & 0 & 0 & 0 & 0 & 0 & 0 & 0 & 0 & 0 \\
Penicillum spp & 0 & 0 & 0 & 0 & 0 & 0 & 0 & 0 & 0 & 0 \\
Botryodiploida theobromae & 0 & 0 & 0 & 0 & 0 & 0 & 0 & 0 & 0 & 0 \\
\hline
\end{tabular}

1. Thuidium gratum; 2, Ectropothecium aeruginosum; 3, Calymperes erosum; 4, Sematophyllum caespitosum; 5, Cyatodium africanum; 6, Radula flacida; 7, Barbula lamberenensis; 8, Sterophyllum radiculosum; 9, Camphylopus aspecicuspis; 10, Frullania spongiosa. Values are mean of replicates.

Rhodobryum giganteum, Lapholejeunea subfusca and Pohlia cruda. The dimension of zones of inhibition measured in millimeter is shown in Tables 1 to 3 below.

For the antibiotic sensitivity assay (Table 5), the anti- biotic that has the highest inhibitory effect on the growth of $S$. aureus is gentamicin, it has an inhibitory zone of $28.0 \mathrm{~mm}$ and for Micrococcus spp. is Pefloxacin with zone of inhibition of $30 \mathrm{~mm}$, while $M$. rouxii has the 
Table 3. Antimicrobial effect of ethanol extracts from bryophytes.

\begin{tabular}{|c|c|c|c|c|c|c|c|c|c|c|}
\hline \multirow{2}{*}{ Microorganism } & \multicolumn{10}{|c|}{ Zone of inhibition (mm) } \\
\hline & 1 & 2 & 3 & 4 & 5 & 6 & 7 & 8 & 9 & 10 \\
\hline Candida albicans & 0 & 0 & 0 & 0 & 0 & 0 & 0 & 0 & 0 & 0 \\
\hline Pseudomonas aeruginosa & 0 & 0 & 0 & 0 & 0 & 0 & 0 & 0 & 0 & 0 \\
\hline Staphylococcus aureus & 0 & 0 & 0 & 0 & 0 & 10.0 & 0 & 0 & 0 & 0 \\
\hline Botrytis cinera & 0 & 0 & 0 & 0 & 0 & 0 & 0 & 0 & 0 & 0 \\
\hline Rhizoctonia solani & 0 & 0 & 0 & 0 & 0 & 0 & 0 & 0 & 0 & 0 \\
\hline Phythium debaryanium & 0 & 0 & 0 & 0 & 0 & 0 & 0 & 0 & 0 & 0 \\
\hline Escherichia coli & 0 & 0 & 0 & 0 & 0 & 0 & 0 & 0 & 0 & 0 \\
\hline Klebsiella spp & 0 & 0 & 0 & 0 & 0 & 0 & 0 & 0 & 0 & 0 \\
\hline Bacillus cereus & 0 & 0 & 0 & 0 & 0 & 0 & 0 & 0 & 0 & 0 \\
\hline Micrococcus spp & 0 & 0 & 0 & 0 & 0 & 0.8 & 0 & 0 & 0 & 0 \\
\hline Proteus spp & 0 & 0 & 0 & 0 & 0 & 0 & 0 & 0 & 0 & 0 \\
\hline Aspergillus flavus & 0 & 0 & 0 & 0 & 0 & 0 & 0 & 0 & 0 & 0 \\
\hline Mucor rouxeii & 0 & 0 & 0 & 0 & 0.9 & 0.8 & 0 & 0 & 0 & 0 \\
\hline Penicillum spp & 0 & 0 & 0 & 0 & 0 & 0 & 0 & 0 & 0 & 0 \\
\hline Botryodiploida theobromae & 0 & 0 & 0 & 0 & 0 & 0 & 0 & 0 & 0 & 0 \\
\hline
\end{tabular}

Table 4. Minimum inhibitory concentrations of water and ethanol extracts of Radula spp. and Cyatodium africanum $(\mu \mathrm{g} / \mathrm{ml})$.

\begin{tabular}{lcccc}
\hline \multirow{2}{*}{ Microorganism } & \multicolumn{2}{c}{ Radula flacida } & \multicolumn{2}{c}{ Cyatodium africanum } \\
\cline { 2 - 5 } & Water & $\mathbf{8 0 \%}$ ethanol & Water & $\mathbf{8 0 \%}$ ethanol \\
\hline S. aureus & 0 & 20.50 & 0 & 0 \\
Micrococcus spp. & 0 & 24.50 & 0 & 0 \\
Mucor rouxii & 26.50 & 0 & 22.60 & 22.60 \\
\hline
\end{tabular}

Table 5. Inhibition zone $(\mathrm{mm})$ of commercial antibiotics on indicator organisms.

\begin{tabular}{lcc}
\hline Antibiotic & S. aureus $(\mathbf{m m})$ & Micrococcus spp. (mm) \\
\hline Septrin $(30 \mu \mathrm{g})$ & 0.0 & 0.0 \\
Chloramphenicol $(30 \mu \mathrm{g})$ & 0.0 & 0.0 \\
Sparfloxacin $(10 \mu \mathrm{g})$ & 0.0 & 0.0 \\
Ciprofloxin $(10 \mu \mathrm{g})$ & 26.0 & 24.0 \\
Amoxcillin $(30 \mu \mathrm{g})$ & 0.0 & 0.0 \\
Augimentin $(30 \mu \mathrm{g})$ & 0.0 & 0.0 \\
Gentamycin $(10 \mu \mathrm{g})$ & 28.0 & 16.0 \\
Pefloxacin $(30 \mu \mathrm{g})$ & 27.0 & 30.0 \\
Tarivid $(10 \mu \mathrm{g})$ & 0.0 & 0.0 \\
Streptomycin $(30 \mu \mathrm{g})$ & 0.0 & 0.0 \\
\hline
\end{tabular}

highest zone of inhibition in Gentamycin with $14 \mathrm{~mm}$. Ketoconazole was used to inhibit fungal growth and the result of the fungal biotest showed that $M$. rouxii has 14.0 $\mathrm{mm}$ zone of inhibition while Penicillium spp. was growing 
without inhibition from the antibiotics used.

\section{DISCUSSION}

The results of this study also show that the tested organisms were susceptible to different concentrations of water and ethanol extracts from $C$. africanum and $R$. flacida, which implies that they have some antimicrobial property. Other workers had earlier ascertained the antimicrobial properties of bryophytes (Oyagade, 1998; Jorgnersteen, 1998; Smith and Reynard, 1992). This implies that these two plants could be used as an alternative for the treatment of infections that could be caused by $S$. aureus, Micrococcus spp. and M. rouxii. $S$. aureus, was susceptible to $80 \%$ ethanol extract of Radula spp. with MIC of $20.50 \mu \mathrm{g} / \mathrm{ml}$ while Mucor rouxii was susceptible to water extract of Radula flacida, with MIC $26.50 \mu \mathrm{g} / \mathrm{ml}$ (Table 4). This result also agrees with the one obtained by Asakawa et al. (1982) who found that $R$. flacida, could inhibit the growth of $S$. aureus at concentrations of 20 to $30 \mathrm{mg} / \mathrm{ml}$. Apart from these two bryophytes, $C$. africanum and $R$. flacida, all other bryophytes used in this study showed no antibacterial activity on the test organisms.

The variation in the susceptibilities of these organisms may be due to the permeability of their cell surface to the fractions obtained from these plants. The antimicrobial properties of the bryophytes observed in this study could be attributed to the phytochemical components, which include polyphenolic compounds such as 3-prenyl bibenzyl from $R$. flacida, and other chemicals like polygodial, norpiquisone and lunularin (Smith and Reynard, 1992). Madson and Paste (1952) in a study discovered antimicrobial substances from almost all plants groups and reported that aqueous extracts of some bryophytes such as Sphagnum portoricense, $S$. antricum, Conocephalum conicum and Dinortiera hirsuts, inhibited the growth of Candida albicans, Pseudomonas aeruginosa and $S$. aureaus.

\section{Conclusion}

The results obtained from this study indicate that fractions obtained from these two bryophytes, $C$. africanum and $R$. flacida, exhibit antimicrobial property on some pathogenic microorganisms. In the light of this, the two bryophytes viz; $C$. africanum and $R$. flacida that are effective can be recommended as source of antimicrobial agents in the treatment of some diseases caused by these etiological agents.

\section{REFERENCES}

Akande AO (1992). A description of and provisional key to some mosses in Ondo State of Nigeria. Niger. J. Bot. 5:145-160.

Alanis AD, Glazada F, Cervantes JA, Terres J, Ceballas GM (2005). Antibacterial properties of some plants used in Mexican traditional medicine for the treatment of gastrointestinal disorders. J. Ethnopharmacol. 100(1-2):153-157. [doi: 10.1016/j.jep.2005.02.022].

Asakawa Y, Takikawa K, Toyotam, Takemoto (1982). Novel Bibenzyl derivatives and ent-cuparene-type sesquiterpenoids from Radula spp. Phytochemistry 21:2481-2490.

Basile A, Vuotto ML, lelpo MTL, Moscatiello V, Ricciardi L, Giordano S, Cobianchi C (1998). Antibacterial activity in Rhynchostegium riparioides (Hedw.) card. extract (Bryophyta). Phytother. Res. 12:146148.

Jorgnersteen JH (1998). Selection of antimicrobial agents for routine testing in clinical microbiology laboratory: diagnosis of microbial infection. Pharmacology 16:245-249.

Madson GC, Paste AL (1952). Occurrence of antimicrobial substances in Chlorophyllose plants growing in Florida. Bot. Gaz. 113:293-300.

Oyagade JO (1998). Antimicrobial efficacy of stem bark extract of Terminalic schimpeliana. Department of Biology Science Research Communication, Unilorin 9:143-149.

Saxena DK, Harinder (2004). Uses of Bryophytes. Resonance

Smith CM, Reynard AM (1992). Textbook of Pharmacology, Saunders, Philadelphia, pp. 362-385.

Subramoniam A, Subhisha S (2005). Bryophytes of India; A potential source of antimicrobial agents in Khan, A. and Khranum, A. editor, Role of Biotechnology in medicinal and aromatic plants, Vol. II Hyderabad, India: Ukaaz publication.

William RB, Bruce AH, Ronald AP (2005). Recent literature on Bryophytes. Bryologist 108(1):158-175. 